\section{Adaptive Prolonged Postreproductive Life Span in Killer Whales}

\author{
Emma A. Foster, ${ }^{1,2}$ Daniel W. Franks, ${ }^{3}$ Sonia Mazzi, ${ }^{4}$ Safi K. Darden, ${ }^{1}$ Ken C. Balcomb, ${ }^{2}$ \\ John K. B. Ford, ${ }^{5}$ Darren P. Croft ${ }^{1}$ *
}

$\mathrm{T}$ he evolution of a prolonged postreproductive life span has attracted considerable interdisciplinary attention, primarily because of the long postmenopausal life span seen in humans (1). Two mechanisms have been proposed to underpin prolonged postreproductive life span: (i) an epiphenomenon of increased longevity, in which evolutionary benefits accrue only during the reproductive phase with no additional fitness benefits after the last reproductive event, and (ii) an evolved adaptation in which postreproductive life span increases the survival of an individual's genes, increasing its inclusive fitness. There is mounting evidence that postreproductive human females increase the reproductive success and survival of their offspring $(2,3)$. Although helping in some postreproductive female cetaceans (4) suggests an adaptive benefit, there has been no evidence that a similar phenomenon occurs in nonhuman animals.

With multigenerational demographic records based on photographic censuses (1974 to 2010) of the Southern and Northern resident killer whale (Orcinus orca) populations in coastal waters off Washington state, USA, and British Columbia, Canada [see (5) for details], we used a Cox proportional hazards model (6) to examine the consequences of a mother's death on offspring survival. ing the study period (6). by directing care toward sons (4).
This unique data set consisted of 589 individually identifiable animals, of which 297 died dur-

Resident killer whales have the longest postreproductive life span of all nonhuman animals: Females stop reproducing in their 30 s to 40 s but can survive into their 90s (5). Because neither sex disperses from the maternal group (7), theory based on kinship dynamics (4) predicts that female's relatedness to her group increases with age and that old mothers maximize their fitness by ensuring their offspring's survival and reproductive success. There is an asymmetry, however, in the benefits of helping sons and daughters. Mating occurs outside of the matriline; thus, a son's offspring are raised by another group (where any rearing costs are incurred), whereas a daughter's offspring are raised within the group, increasing within-group competition (4). Old mothers can therefore maximize inclusive fitness benefits

Postreproductive mothers are known to have little effect on their daughter's reproductive success in resident killer whales (8). However, we show that both postreproductive and reproductive females increase their own offspring's survival, particularly older male offspring (Fig. 1 and table S1). For male offspring $\leq 30$ years old, there is a 3.1-

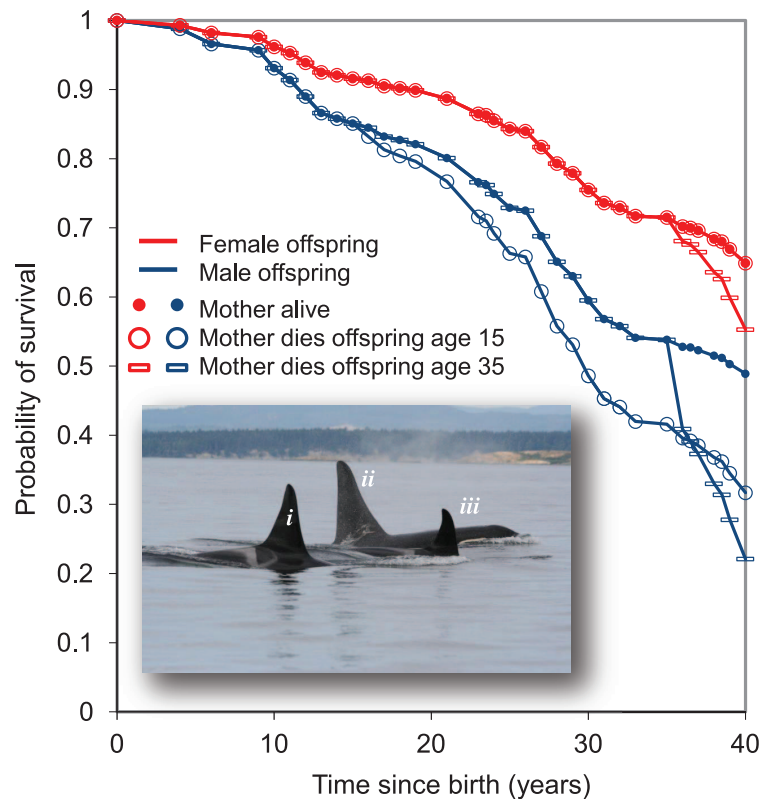

Fig. 1. Survival curves derived from a Cox proportional hazards model (6) for male and female offspring experiencing their mother's death at different ages. (Inset) Adult sons ( $i$ and ii) traveling with their postreproductive mother (iii). fold increase in mortality risk in the year after their mother's death (Fig. 1). For males $>30$, this risk increases to 8.3-fold (Fig. 1). In contrast, female offspring $\leq 30$ show no increase in mortality risk, whereas those $>30$ show some increase in risk (2.7-fold) in the year after their mother's death (Fig. 1). Importantly, the magnitude of this effect does not differ between reproductive and postreproductive females (6). Indeed, for offspring $>30$, the death of a postreproductive mother increases mortality risk 13.9-fold in sons and 5.4-fold in daughters in the year after their mother's death.

Our results demonstrate an adaptive benefit to a prolonged postreproductive life span in killer whales. Because reproductive success increases with age in male killer whales (9), increasing the survival of older male offspring will maximize inclusive fitness (4). Resident killer whales are unusual in that mothers maintain strong social relations with their adult sons throughout their lives (7). Mothers may increase the survival of their adult sons in a number of ways, including assisting in foraging and providing support during agonistic encounters (10). Crucially, the fact that mothers increase the survival of male offspring, which do not terminate reproduction early (9), may explain why killer whales have evolved the longest postreproductive life span of any nonhuman animal.

\section{References and Notes}

1. K. Hill, A. M. Hurtado, Nature 483, 160 (2012).

2. M. Lahdenperä, V. Lummaa, S. Helle, M. Tremblay, A. F. Russell, Nature 428, 178 (2004).

3. M. A. Cant, R. A. Johnstone, Proc. Natl. Acad. Sci. U.S.A. 105, 5332 (2008).

4. R. A. Johnstone, M. A. Cant, Proc. Biol. Sci. 277, 3765 (2010).

5. P. F. Olesiuk, M. A. Bigg, G. M. Ellis, Rep. Int. Whaling Comm. 12, 209 (1990).

6. Materials and methods are available as supplementary materials on Science Online.

7. M. A. Bigg, P. F. Olesiuk, G. M. Ellis, J. K. B. Ford, K. C. Balcomb, Rep. Int. Whaling Comm. 12, 383 (1990).

8. E. J. Ward, K. M. Parsons, E. E. Holmes, K. C. Balcomb 3rd, J. K. B. Ford, Front. Zool. 6, 4 (2009).

9. M. J. Ford et al., J. Hered. 102, 537 (2011).

10. R. W. Baird, in Cetacean Societies: Field Studies of Dolphins and Whales, J. Mann, R. Connor, P. L. Tyack, H. Whitehead, Eds. (University of Chicago Press, Chicago, 2000), pp. 127-153.

Acknowledgments: We thank our colleagues for their important roles in data collection over the past 35 years, particularly M. Bigg, D. Ellifrit, G. Ellis, E. Heydenrich, and A. van Ginneken and the Biotechnology and Biological Sciences Research Council and the Leverhulme Trust for funding. Data are available in the supplementary materials.

Supplementary Materials

www.sciencemag.org/cgi/content/ful//337/6100/1313/DC1 Materials and Methods

2 May 2012; accepted 27 July 2012

10.1126/science.1224198

${ }^{1}$ Centre for Research in Animal Behaviour, College of Life and Environmental Sciences, University of Exeter, Exeter EX4 4QG, UK. ${ }^{2}$ Center for Whale Research, 355 Smugglers Cove Road, Friday Harbor, WA 98250, USA. ${ }^{3}$ Department of Biology, University of York, York YO10 5DD, UK. ${ }^{4}$ Department of Mathematics, University of York, York Y010 5DD, UK. ${ }^{5}$ Pacific Biological Station, Fisheries and Oceans Canada, Nanaimo, BC V9T 6N7, Canada.

${ }^{*}$ To whom correspondence should be addressed. E-mail: d.p.croft@exeter.ac.uk 